\title{
Nucleosomes in Pancreatic Cancer Patients during Radiochemotherapy
}

\author{
Andreas Kremer ${ }^{a}$ Ralf Wilkowski ${ }^{b}$ Stefan Holdenrieder ${ }^{a}$ Dorothea Nagel ${ }^{a}$ \\ Petra Stieber $^{a}$ Dietrich Seidel $^{a}$
}

Institutes of a Clinical Chemistry and ${ }^{\mathrm{b}}$ Radiotherapy and Radiooncology, Klinikum der Universität München Grosshadern, Munich, Germany

\section{Key Words}

Nucleosomes · Pancreatic cancer · Radiochemotherapy · Cell death $\cdot$ Apoptosis

\begin{abstract}
Nucleosomes appear spontaneously in elevated concentrations in the serum of patients with malignant diseases as well as during chemo- and radiotherapy. We analyzed whether their kinetics show typical characteristics during radiochemotherapy and enable an early estimation of therapy efficacy. We used the Cell Death Detection Eli$\mathrm{sa}^{\text {plus }}$ (Roche Diagnostics) and investigated the course of nucleosomes in the serum of 32 patients with a local stage of pancreatic cancer who were treated with radiochemotherapy for several weeks. Ten of them received postsurgical therapy, 21 received primary therapy and 1 received therapy for local relapse. Blood was taken before the beginning of therapy, daily during the first week, once weekly during the following weeks and at the end of radiochemotherapy. The response to therapy was defined according to the kinetics of CA 19-9: a decrease of CA 19-9 $\geq 50 \%$ after radiochemotherapy was considered as 'remission'; an increase of $\geq 100 \%$ (which was confirmed by two following values) was defined as 'progression'. Patients with 'stable disease' ranged intermediately. Most of the examined patients showed a decrease of the concentration of nucleosomes within $6 \mathrm{~h}$ after the first dose of radiation. Afterwards, nucleosome levels increased rapidly, reaching their maximum during the following days.
\end{abstract}

Patients receiving postsurgery, primary or relapse therapies did not show significant differences in nucleosome values during the time of treatment. Single nucleosome values, measured at 6, 24 and $48 \mathrm{~h}$ after the application of therapy, could not discriminate significantly between patients with no progression and those with progression of disease. However, the area under the curve of the first 3 days, which integrated all variables of the initial therapeutic phase, showed a significant correlation with the progression-free interval $(p=0.008)$. Our results indicate that the area under the curve of nucleosomes during the initial phase of radiochemotherapy could be valuable for the early prediction of the progression-free interval.

Copyright @ 2005 S. Karger AG, Basel

\section{Introduction}

For cellular homeostasis in humans, a balance between cellular proliferation and elimination is of great importance [1]. Several physiological and pathological stimuli lead to cell death. In case of lethal cell damage, apoptotic cell death is induced by the activation of a cascade of enzymes. During this procedure, many cellular structures are degraded by activated caspases. Chromatin is cleaved by endonucleases at the DNA-linking sites into monoand oligonucleosomes [1-4]. These are composed of a core particle of histones and DNA that is twisted around it $[5,6]$. During apoptosis, these particles are phagocytized by neighboring cells and macrophages or are re-

\begin{tabular}{ll}
\hline KARGER & ( ) 2005 S. Karger AG, Basel \\
1010-4283/05/0261-0044\$22.00/0 \\
$\begin{array}{l}\text { Fax +4161306 12 34 } \\
\begin{array}{l}\text { E-Mail karger@karger.ch } \\
\text { www.karger.com }\end{array}\end{array}$ & $\begin{array}{l}\text { Accessible online at: } \\
\text { www.karger.com/tbi }\end{array}$
\end{tabular}

Dr. Petra Stieber

Institute of Clinical Chemistry, Klinikum der Universität München Grosshadern Marchioninistrasse 15, DE-81377 München (Germany)

Tel. +49 897095 3115, Fax +49 8970956298

E-Mail Petra.Stieber@med.uni-muenchen.de 
leased into circulation $[1,2]$. There they can be quantified by immunological methods [7]. Nucleosomes can be detected in low amounts in the serum of healthy individuals $[8,9]$ and appear in higher concentrations in the serum of patients with various benign and malignant diseases [reviewed in 10], such as in patients suffering from autoimmune diseases [11, 12], after trauma [13], during graft rejection [14, 15], after stroke [16], as well as in cancer patients, spontaneously and during chemo- and radiotherapy $[9,17,18]$.

After the disintegration of the cell membrane, nucleosomes are released into circulation and are quickly eliminated [19]. Thus, the concentration of nucleosomes in the serum can be considered a correlative for the extent of cell death at a certain time. In patients with malignant diseases, the spontaneous rate of cell death might contain information on the tumor activity, whereas the induced rate of cell death during chemo- or radiotherapy might indicate the effects of the treatment.

Nowadays, the efficacy of therapy in patients with solid tumors is mostly controlled by imaging techniques like ultrasonography, X-ray, computed tomography, magnetic resonance tomography and positron emission tomography. Particularly in pancreatic cancer, it often takes a long time until the effects of radiotherapy on the tumor can be estimated by these imaging techniques. In addition, the local effects of the applied therapy alter the surrounding tissue structure in the irradiation field, hampering an objective judgment of the actual tumor size. However, it would be very useful to know the tumor response to radiochemotherapy as early as possible, in order to optimize the therapeutic protocol and to avoid unnecessary side effects. Therefore, we investigated the courses of nucleosomes in the serum of patients with pancreatic cancer during radiochemotherapy, asking whether typical kinetic patterns of nucleosomes occur and whether they can early predict the efficacy of therapy.

\section{Methods and Patients}

\section{Methods}

For the quantification of nucleosome concentrations in serum, we used the Cell Death Detection Elisa ${ }^{\text {plus }}$ (Roche Diagnostics). Two monoclonal mouse antibodies, which are directed against histones and DNA, respectively, catch the nucleosomes specifically. The antihistone antibody additionally binds to the microtiter plate, and the anti-DNA antibody, which is labeled with peroxidase, reacts with the 2,2'-azino-di(3-ethylbenzthiazolin-sulfonate) substrate. The amount of nucleosomes which are captured by the antibodies is proportional to the resulting color development and enables the photometric quantification in arbitrary units (AU).

Nucleosomes in Pancreatic Cancer Patients

during Radiochemotherapy
We used serum samples for the determination of nucleosomes and performed the preanalytical handling of the samples as described in Holdenrieder et al. [7]; that is, within 1-2 $\mathrm{h}$ after venipuncture, the blood samples were centrifuged at $3,000 \mathrm{~g}$ for $15 \mathrm{~min}$. Subsequently, the serum samples were stabilized by adding $10 \mathrm{~m} M$ EDTA and stored at $-80^{\circ} \mathrm{C}$. Prior to the measurement of nucleosomes, samples were thawed, homogenized and diluted 1:4 with an incubation buffer. The course of nucleosomes of 1 patient was determined within one run of the enzyme immunoassay to minimize the methodical variance.

In addition, we examined CA 19-9 by Elecsys 2010 (Roche Diagnostics) in all serum samples.

\section{Patients}

In total, 32 patients with pancreatic cancer were included in our study. All patients were treated with a combination of radio- and concurrent chemotherapy. Among them were 10 with postsurgery therapy, 21 with primary therapy and 1 with local relapse therapy.

Radiotherapy was applied in single fractions of 1.8-2.0 Gy for 5 days a week over a period of 5 weeks up to a total dose rate of 45 50 Gy (dose rate according to ICRU 50). In addition, gemcitabine $\left(300 \mathrm{mg} / \mathrm{m}^{2}\right)$ and cisplatin $\left(30 \mathrm{mg} / \mathrm{m}^{2}\right)$ were applied on days $1,8,22$ and 29 or, alternatively, gemcitabine $\left(300 \mathrm{mg} / \mathrm{m}^{2}\right)$ on days 1,15 and 29 and 5-fluorouracil $\left(350 \mathrm{mg} / \mathrm{m}^{2}\right)$ daily. Blood was taken before the beginning of therapy, $6 \mathrm{~h}$ after the first radiation, daily during the first week, once weekly during the following weeks and at the end of radiochemotherapy. Some patients were also followed up several months after radiochemotherapy. The observation time of all patients was 1.7-16 months. Before the first venipuncture, all patients having been recruited for this study gave their written informed consent. The study was approved by the local ethical committee.

Regarding the response to therapy, patients were subdivided into groups depending on the change of CA 19-9 up to 2 months after the end of therapy. A decrease of $\geq 50 \%$ of the pretherapeutic CA 19-9 value was considered as partial remission $[20,21]$. Progressive disease was defined as an increase of CA 19-9 $\geq 100 \%$ which was confirmed by two further results with increased values [22]. Patients with stable disease ranged intermediately.

The progression-free interval was defined as the time without increase $\geq 100 \%$ of the pretherapeutic CA $19-9$ value.

\section{Statistics}

For our evaluation, we combined the patients with partial remission and stable disease into 'no progression'. They were compared with patients who suffered from progressive disease. For the statistical analysis of the difference between the two groups, the Wilcoxon test was used. For the analysis of the progression-free interval, we used the Kaplan-Meier method and the log-rank test. The medians of the whole sample were used as cut-offs. A p value $<0.05$ was considered statistically significant. All calculations were performed by software of SAS (version 8.2, SAS Institute Inc., Cary, N.C., USA).

\section{Results}

Concerning the response to therapy, 8 out of the 32 patients showed a partial remission, 17 had stable disease and 7 developed metastases, which were discovered at 


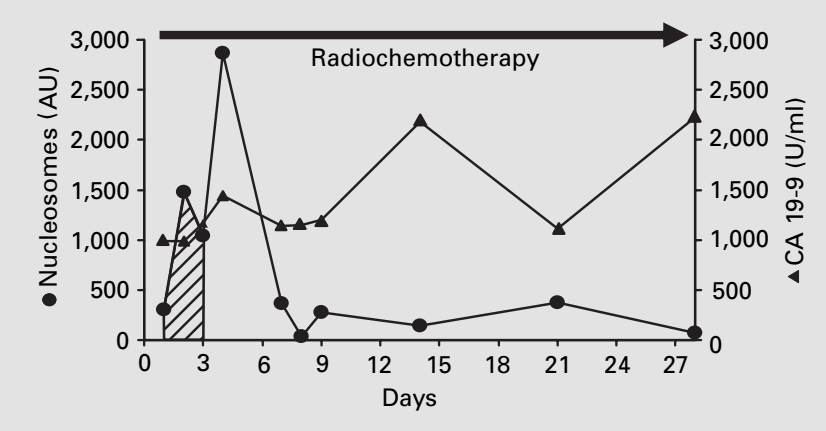

Fig. 1. Course of nucleosomes of a patient with pancreatic cancer during primary radiochemotherapy who suffered from progression of disease, according to CA 19-9 kinetics. Nucleosome levels show a considerable increase during the first week of the therapy, resulting in a large AUC.

the end of therapy. Ten patients underwent surgery and received postsurgery radiochemotherapy. Eight among them showed stable disease and 2 developed metastases until the end of therapy. Twenty-one patients were treated with primary radiochemotherapy. Eight among them reached a remission, 8 had stable disease and 5 suffered from progressive disease. The patient with local relapse had a stable disease.

Regarding the progression-free interval, 15 (median: 9.7 months) out of 32 patients had no progression, whereas 17 patients (median: 6.1 months) developed systemic metastases during the observation time.

Most of the examined patients showed a significant decrease of the concentration of nucleosomes within $6 \mathrm{~h}$ after the first radiation fraction had been applied. Nucleosome levels were rising again rapidly, reaching the maximum during the following days. Figures 1 and 2 show typical courses of nucleosome concentrations during radiochemotherapy for 1 patient suffering from progression and 1 with a remission of disease, according to the kinetics of CA 19-9.

No significant differences in nucleosome values during the time of treatment were observed in patients receiving postsurgery, primary and relapse therapy concerning the pretherapeutic value or the values during the following 3 days (day 1 (6 h), day 2, day 3), as well as for the minimal value, the maximal value, the area under the curve during the first week $\left(\mathrm{AUC}_{1-7}\right)$ and the area under the curve during the first 3 days $\left(\mathrm{AUC}_{1-3}\right)$. Therefore, the results from all patients were combined for the evaluation of the prediction of therapy efficacy by nucleosomes in the serum (table 1).

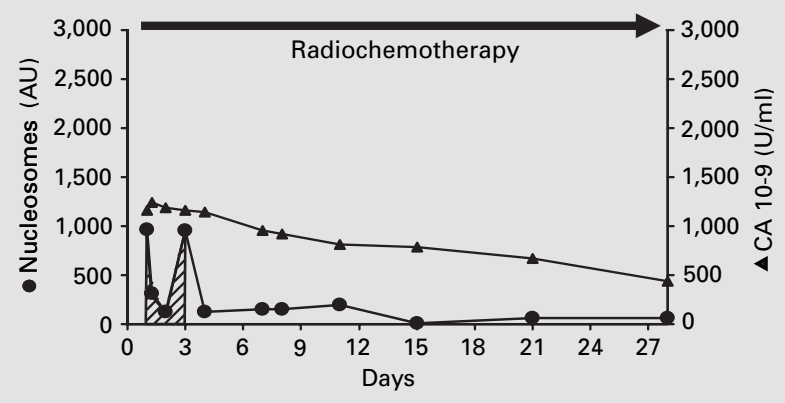

Fig. 2. Course of nucleosomes of a patient with pancreatic cancer during primary radiochemotherapy with remission of disease. The increase of nucleosome concentrations during the initial phase of the treatment is less pronounced, resulting in a smaller AUC.

Table 1. Median and range of nucleosome values of several variables during the first week

\begin{tabular}{llll}
\hline & $\begin{array}{l}\text { Postsurgery } \\
\text { therapy }\end{array}$ & $\begin{array}{l}\text { Primary + relapse } \\
\text { therapy }\end{array}$ & $\begin{array}{l}\mathrm{p} \\
\text { value }\end{array}$ \\
\hline Before therapy & $581(278-1,836)$ & $581(278-1,836)$ & 0.611 \\
Day 1 (6 h) & $417(267-842)$ & $364(116-1,322)$ & 0.616 \\
Day 2 & $529(121-2,404)$ & $601(123-6,362)$ & 0.627 \\
Day 3 & $396(198-1,385)$ & $758(193-2,883)$ & 0.353 \\
Minimum & $247(100-829)$ & $220(39-611)$ & 0.708 \\
Maximum & $1,378(599-3,965)$ & $1,390(442-6,901)$ & 0.878 \\
AUC $_{1-7}$ & $4,560(2,285-10,232)$ & $4,655(1,819-18,173)$ & 0.982 \\
AUC $_{1-3}$ & $962(508-3,284)$ & $1,107(455-6,640)$ & 0.438 \\
\hline
\end{tabular}

In order to prove the validity of the biochemical response to therapy by CA 19-9 as a secondary end-point for the success of radiochemotherapy, it was tested for its correlation with the overall survival. Patients with biochemically no progression (increase of CA $19-9<100 \%$ ) showed a significantly longer overall survival than patients with biochemical progression of disease (increase of CA $19-9 \geq 100 \%$; $p=0.025$; fig. 3 ).

Concerning the biochemical response to therapy by CA 19-9, nucleosomes showed slightly lower values for patients with no progression compared with those with progression for the 6-hour value (median: $367 \mathrm{AU}$; no progression: $50 \%>$ median, progression: $67 \%>$ median; $p=$ 0.590), the value at day 1 (median: $601 \mathrm{AU}$; no progression: $48 \%>$ median, progression: $67 \%>$ median; $\mathrm{p}=$ 0.411 ), the value at day 2 (median: $651 \mathrm{AU}$; no progres- 


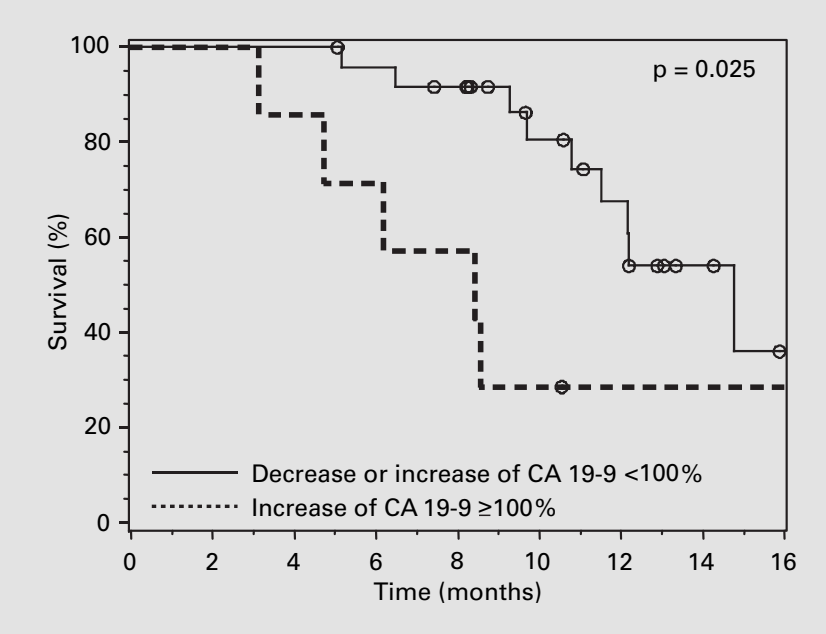

Fig. 3. Correlation of the biochemical response to therapy by CA 19-9 with the overall survival. Patients with biochemically no progression (increase of CA 19-9<100\%) showed a significantly longer overall survival than patients with biochemical progression of disease (increase of CA $19-9 \geq 100 \% ; p=0.025$ ).

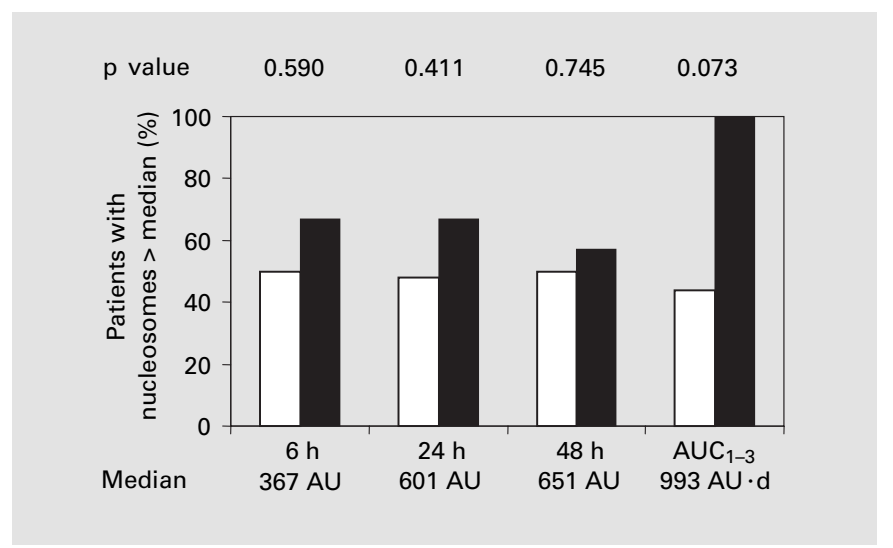

Fig. 4. Percentage of patients with no progression ( $\square$ ) and with progression $(\boldsymbol{\square})$ of disease after radiochemotherapy exhibiting nucleosome values (AU) higher than the median of all patients investigated. The discriminating power between both groups is indicated by $\mathrm{p}$ values $\left(\chi^{2}\right)$ for the nucleosome values 6, 24, $48 \mathrm{~h}$ after the application of therapy and the $\mathrm{AUC}_{1-3}$ which integrated all variables of the initial therapeutic phase.

sion: $50 \%>$ median, progression: $57 \%>$ median; $\mathrm{p}=$ 0.745) and particularly for the $\mathrm{AUC}_{1-3}$ (median: $993 \mathrm{AU} \cdot \mathrm{d}$; no progression: $44 \%>$ median, progression: $100 \%>$ median; $p=0.073$ ), although this had only borderline significance (fig. 4).

The $\mathrm{AUC}_{1-3}$ integrated the information of all variables during the initial phase of the therapy and revealed a

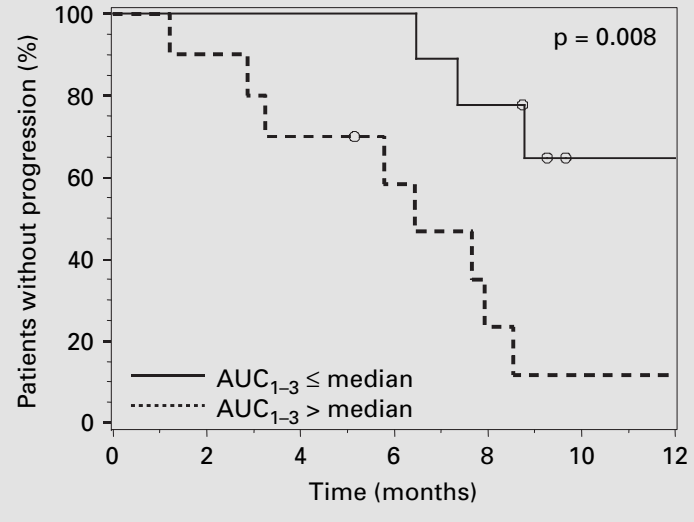

Fig. 5. Correlation of the $\mathrm{AUC}_{1-3}$ and the progression-free interval. Patients with $\mathrm{AUC}_{1-3}$ smaller than the median were shown to have a significantly longer progression-free interval than those with $\mathrm{AUC}_{1-3}$ higher than the median $(\mathrm{p}=0.008)$.

potential for the early prediction of the progression-free interval: patients with an $\mathrm{AUC}_{1-3}$ lower than the median (993 AU.d) corresponded with a significantly longer progression-free interval compared with those with higher values ( $p=0.008$; fig. 5 ).

\section{Discussion}

Nowadays, there are various therapeutic options in oncological diseases. In early stages, the primary approach is often the complete resection of the tumor. Subsequent postsurgery therapies like chemo- or radiochemotherapy are added in many cases to eliminate remaining tumor cells. Concerning radiotherapy, a fractionated protocol protects especially benign tissues, as they are more capable of repairing DNA damage effectively during the radiation-free interval than malignant cells [23]. If there is lethal damage, cells might undergo apoptotic cell death resulting in the release of mono- and oligonucleosomes into circulation $[1,24,25]$.

It is known that in tumor tissue, massive cell proliferation and cell death exist at the same time. This turnover of cells, including the release of apoptotic products, varies between different kinds of cancers and also between individuals [26]. As pancreatic cancer is often diagnosed only in advanced stages, we expected to find high rates of nucleosomes pretherapeutically as well as during therapy. 
The course of nucleosomes typically started at a high level and decreased $6 \mathrm{~h}$ after the first application, followed by a rapid increase reaching the maximum during the following days.

Already the first radiation might lead to strong physical and chemical changes, such as a change of the ionic setting, the production of free radicals and reactive products resulting in alterations of many cell structures and biological cell damage. On the DNA level, changes appear primarily in the form of single-strand breaks [27]. In order to enable the repair of the damage, cells are commonly arrested in the $\mathrm{G}_{0}$ phase. In the case of successful repair, they will continue their cell cycle from the $G_{1}$ phase to the $\mathrm{S}$ phase. If the damage is too severe, cells will mainly undergo apoptotic cell death after a certain time of delay [24, 28-30]. Subsequently, various apoptotic products like nucleosomes are released into circulation. This scenario would explain the decrease of the nucleosome values $6 \mathrm{~h}$ after the first application followed by the steep increase.

Besides tumor cells, normal cells - particularly those with a high proliferation rate - might also be affected by radiochemotherapy [31, 32] and contribute to the increase of the amount of nucleosomes in circulation. We questioned whether this was just a minor effect and compared the nucleosome concentrations in patients with postsurgery and primary radiochemotherapy. The former received tumor resection before therapy and were supposed to be free of any tumor burden, whereas the latter still had obvious tumor masses. Because we could not find substantial differences concerning the nucleosome levels in both groups, we reinvestigated the pathological outcome of the resected patients. Interestingly, in none of the patients could the tumor be removed with the required safety margins, which means that in all patients with postsurgery radiochemotherapy, microscopic tumor residues were still present.

As shown by a recent in vitro study on normal and malignant lung cell lines that were irradiated with various dose rates, the release of nucleosomes was significantly higher in tumor cells than in normal bronchial cells after irradiation with low-dose rates [33]. However, as the volumes of tumor and normal tissues in the radiation field might differ and 'normal' tissue might consist of various cell types with different radiosensitivities, it is difficult to indicate the exact contribution of normal and malignant tissues to the release of nucleosomes in vivo.

Pancreatic cancer is known to be an aggressive disease with limited prognosis. If a primary resection of the tumor is not possible, radiochemotherapy nowadays is consid- ered as standard palliative therapy aiming at the prolongation of the progression-free interval [34, 35]. The response to therapy can be controlled either by imaging techniques or by oncological biomarkers as correlates. Current experiences encourage the use of oncological biomarkers such as CA 19-9 that indicate the biochemical response in time [36, 37], whereas the evaluation by imaging techniques is often not standardized, implicating considerable variations due to different technique and investigator standards. However, to estimate early the response to therapy - which would be helpful for the management of the treatment - biochemical markers with high tumor specificity and serum kinetics that are associated with therapy would be useful.

Although nucleosomes in the serum are lacking tumor specificity, they have a short half-life under physiological conditions [38, 39] and show characteristic courses with considerable peaks during the first week of therapy. Therefore, we supposed that they had predictive potential already at the initial phase of therapy.

Concerning therapy response, single nucleosome values at defined time points unfortunately could not discriminate significantly between patients with no progression and those with progression of disease. The $\mathrm{AUC}_{1-3}$, which integrated all variables of the initial therapeutic phase, also showed only a borderline-significant correlation with therapy response. However, regarding the progression-free interval, the AUC distinguished significantly between patients who suffered from early progression and those with later progression.

This observation might indicate an association of nucleosome release, tumor growth and treatment effect: high concentrations of nucleosomes during therapy could be explained by aggressive tumors with high proliferation and cell death rates. During the time between the applications of radiochemotherapy, new subpopulations of undifferentiated and fragile tumor cells might surge [40], leading to high cell death rates during the following applications and to high nucleosome levels in the serum. Although these tumors might show initial responses to the treatment, they are at high risk to recur and progress soon. Thus, high nucleosome concentrations at the initial phase of therapy might be linked to tumors with high aggressiveness and an inefficient long-term response to therapy.

In conclusion, our results indicate that the $\mathrm{AUC}_{1-3}$ of nucleosomes could be a valuable marker for the early estimation of the progression-free interval in patients with pancreatic cancer receiving radiochemotherapy. 


\section{References}

1 Kerr JF, Winterford CM, Harmon BV: Apoptosis. Its significance in cancer and cancer therapy. Cancer 1994;73:2013-2026.

2 Wyllie AH, Arends MJ, Morris RG, Walker SW, Evan G: The apoptosis endonuclease and its regulation. Semin Immunol 1992;4:389397.

3 Arends MJ, Morris RG, Wyllie AH: Apoptosis. The role of the endonuclease. Am J Pathol 1990;136:593-608.

4 Enari M, Sakahira H, Yokoyama H, Okawa K, Iwamatsu A, Nagata S: A caspase-activated DNase that degrades DNA during apoptosis, and its inhibitor ICAD. Nature 1998;391:4350

5 Kornberg R, Lorch Y: Twenty-five years of the nucleosome, fundamental particle of the eukaryote chromosome. Cell 1999;98:285-294.

6 Luger K: Structure and dynamic behavior of nucleosomes. Curr Opin Genet Dev 2003;13: 127-135.

7 Holdenrieder S, Stieber P, Bodenmüller $\mathrm{H}$, Fertig G, Fürst H, Schmeller N, Untch M, Seidel D: Nucleosomes in serum as a marker for cell death. Clin Chem Lab Med 2001;39:596605.

8 Holdenrieder S, Stieber P, Förg T, Kuehl M, Schulz L, Busch M, Schalhorn A, Seidel D: Apoptosis in serum of patients with solid tumours. Anticancer Res 1999;19:2721-2724.

9 Holdenrieder S, Stieber P, Bodenmüller $\mathrm{H}$, Busch M, Fertig G, Fürst H, Schalhorn A, Schmeller N, Untch M, Seidel D: Nucleosomes in serum of patients with benign and malignant diseases. Int J Cancer 2001;95:114-120.

10 Ziegler A, Zangenmeister-Wittke U, Stahel RA: Circulating DNA: A new diagnostic gold mine? Cancer Treat Rev 2002;28:255-271.

11 Amoura Z, Piette JC, Chabre H, Cacoub P, Papo T, Wechsler B, Bach JF, Koutouzov S: Circulating plasma levels of nucleosomes in patients with systemic lupus erythematosus: Correlation with serum antinucleosome antibody titers and absence of clear association with disease activity. Arthritis Rheum 1997; 40:2217-2225.

12 Van Nieuwenhuijze AE, van Lopik T, Smeenk RJ, Aarden LA: Time between onset of apoptosis and release of nucleosomes from apoptotic cells: Putative implications for systemic lupus erythematosus. Ann Rheum Dis 2003;62:1014.

13 Lo YM, Rainer TH, Chan LY, Hjelm NM, Cocks RA: Plasma DNA as a prognostic marker in trauma patients. Clin Chem 2000;46:319_ 323.

14 Lo YM, Tein MS, Pang CC, Yeung CK, Tong KL, Hjelm NM: Presence of donor-specific DNA in plasma of kidney and liver-transplant recipients. Lancet 1998;351:1329-1330.
15 Fishbein TM, Liu J, Wang L, Li Y, Boros P: Increased apoptosis is specific for acute rejection in rat small bowel transplant. J Surg Res 2004;119:51-55.

16 Rainer TH, Wong LK, Lam W, Yuen E, Lam NY, Metreweli C, Lo YM: Prognostic use of circulating plasma nucleic acid concentrations in patients with acute stroke. Clin Chem 2003; 49:562-569.

17 Kuroi K, Tanaka C, Toi M: Clinical significance of plasma nucleosome levels in cancer patients. Int J Oncol 2001;19:2721-2724.

18 Holdenrieder S, Stieber P, Bodenmüller $\mathrm{H}$, Busch M, Von Pawel J, Schalhorn A, Nagel D, Seidel D: Circulating nucleosomes in serum. Ann N Y Acad Sci 2001;945:93-102.

19 Rumore P, Muralidhar B, Lin M, Lai C, Steinman CR: Hemodialysis as a model for studying endogenous plasma DNA: Oligonucleosomelike structure and clearance. Clin Exp Immunol 1992;90:56-62.

20 Ishii H, Okada S, Sato T, Wakasugi H, Saisho H, Furuse J, Ishikawa O, Matsuno S, Yokoyama S: CA 19-9 in evaluating the response to chemotherapy in advanced pancreatic cancer. Hepatogastroenterology 1997;44:279-283.

21 Heinemann V, Schermuly MM, Stieber P, Schulz L, Jungst D, Wilkowski R, Schalhorn A: CA 19-9: A predictor of response in pancreatic cancer treated with gemcitabine and cisplatin. Anticancer Res 1999;19:2433-2435.

22 Nishida K, Kaneko T, Yoneda M, Nakagawa S, Ishikawa T, Yamane E, Nishioka B, Miyamoto Y, Takano H, Yoshikawa T, Kondo M: Doubling time of serum CA $19-9$ in the clinical course of patients with pancreatic cancer and its significant association with prognosis. J Surg Oncol 1999;71:140-146.

23 Schaer P: Spontaneous DNA damage, genome instability, and cancer - When DNA replication escapes control. Cell 2001;104:329-332.

24 Mirkovic N, Meyn RE, Hunter NR, Milas L: Radiation-induced apoptosis in a murine lymphoma in vivo. Radiother Oncol 1994;33:1116.

25 Mirzaie-Joniani H, Eriksson D, Sheikholvaezin A, Johansson A, Löfroth PO, Johansson L, Stigbrand T: Apoptosis induced by low-dose and low-dose-rate radiation. Cancer 2002;94: 1210-1214.

26 Meyn RE, Stephens LC, Ang KK, Hunter NR, Brock WA, Milas L, Peters LJ: Heterogeneity in the development of apoptosis in irradiated murine tumours of different histologies. Int $\mathbf{J}$ Radiat Biol 1993;64:583-591.

27 McMillan TJ, Tobi S, Mateos S, Lemon C: The use of DNA double-strand break quantification in radiotherapy. Int $\mathrm{J}$ Radiat Oncol Biol Phys 2001;49:373-377.
28 Leist M, Nicotera P: The shape of cell death. Biochem Biophys Res Commun 1997;236:19.

29 Szumiel I: Monitoring and signaling of radiation-induced damage in mammalian cells. Radiat Res 1998;150:92-101.

30 Sionov RV, Haupt Y: The cellular response to p53: The decision between life and death. Oncogene 1999; 18:6145-6157.

31 Hendry JH, West CM: Apoptosis and mitotic cell death: Their relative contributions to normal-tissue and tumour radiation response. Int $\mathrm{J}$ Radiat Biol 1997;71:709-719.

32 Hendry JH: Genomic instability: Potential contributions to tumour and normal tissue response, and second tumours, after radiotherapy. Radiother Oncol 2001;59:117-126.

33 Holdenrieder S, Stief J, Bergner A, Gamarra F, Mitlewski A, Nagel D, Huber RM, Stieber P. Nucleosomes indicate the in vitro radiosensitivity of irradiated broncho-epithelial and lung cancer cells. Tumor Biol 2004;25:321-326.

34 Wilkowski R, Heinemann V, Rau H: Locally advanced pancreatic carcinoma. Radiochemotherapy prolongs survival. MMW Fortschr Med 2000;142:31-32.

35 Heinemann V: Present and future treatment of pancreatic cancer. Semin Oncol 2002;29:2331

36 Stemmler J, Stieber P, Szymala AM, Schalhorn A, Schermuly MM, Wilkowski R, Helmberger T, Lamerz R, Stoffregen C, Niebler K, Garbrecht M, Heinemann V: Are serial CA 19-9 kinetics helpful predicting survival in patients with advanced or metastatic pancreatic cancer treated with gemcitabine and cisplatin? Onkologie 2003;26:462-467.

37 Micke O, Bruns F, Kurowski R, Horst E, deVries AF, Hausler JW, Willich N, Schaefer U: Predictive value of carbohydrate antigen 19-9 in pancreatic cancer treated with radiochemotherapy. Int J Radiat Oncol Biol Phys 2003;57: 90-97.

38 Gauthier VJ, Tyler LN, Mannik M: Blood clearance kinetics and liver uptake of mononucleosomes in mice. J Immunol 1996;156:11511156 .

39 Atamaniuk J, Vidotto C, Tschan H, Bachl N, Stuhlmeier KM, Müller MM: Increased concentrations of cell-free plasma DNA after exhaustive exercise. Clin Chem 2004;50:16681670 .

40 Thames HD, Ruifrok AC, Milas L, Hunter N, Mason KA, Terry NH, White RA: Accelerated repopulation during fractionated irradiation of a murine ovarian carcinoma: Downregulation of apoptosis as a possible mechanism. Int $\mathrm{J}$ Radiat Oncol Biol Phys 1996;35:951-962. 